\title{
Pre-operative assessment of impacted mandibular third molar and inferior alveolar canal using orthopantomograhpy and cone beam computed tomography
}

\author{
Mahmuda Akter, Quazi Billur Rahman, Md. Wares Uddin, Gokul Chand Kundu, Samir Banik and \\ Ashik Abdullah Imon
}

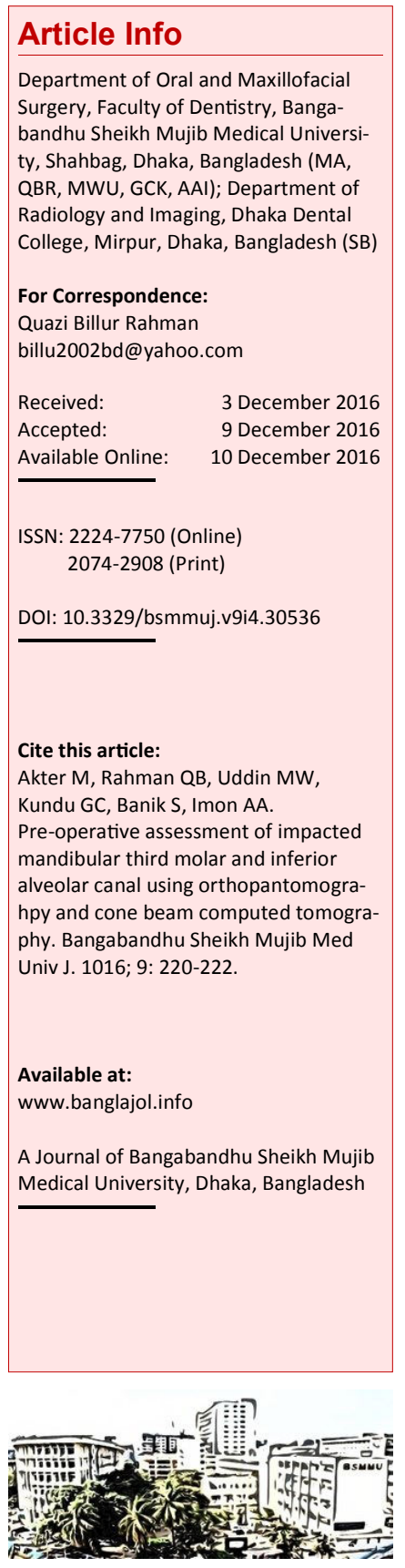

\section{Abstract}

The aim of this study was to assess the proximity and relation of impacted mandibular third molar and inferior alveolar canal on orthopantomogram and cone beam computed tomography (CBCT). Sixty impacted mandibular third molars having close proximity with the inferior alveolar canal were included. CBCT images were done to determine the exact location and relationship of impacted third molar tooth and inferior alveolar canal. We assessed the radiographic signs from orthopantomogram, the course of inferior alveolar canal and proximity to the third molar tooth in CBCT. The buccal course of inferior alveolar canal was most frequently detected $(n=36)$ in CBCT findings. The impacted lower third molar roots were $55 \%$ contact with the inferior alveolar canal and $45 \%$ separate from the canal. On orthopantomogram, the following signs were strongly correlated with actual contact: Superimposed relationship between the third molar and the inferior alveolar canal. CBCT is useful as a presurgical planning in patients with impacted mandibular third molar showing close proximity to the inferior alveolar canal.

\section{Introduction}

The extraction of lower third molar is most common surgical procedure in maxillofacial surgery. There is a chance of inferior alveolar nerve damage due to close approximate between third molar tooth and inferior alveolar nerve. 1 Permanent damage of inferior alveolar nerve during third molar extraction is very low, but a significant number of patients are affected due to sensory loss of inferior alveolar nerve.., 3

There is a chance of temporary inferior alveolar nerve injury increases due to close approximation between third molar and inferior alveolar canal is observed radiologically. Assessment of third molar position and establish the anatomical relationship of with the inferior alveolar canal preoperatively is important for reducing the risk of nerve injury.

Orthopantomography is commonly used diagnostic tool for third molar extraction. Two dimensional panoramic radiographs provide limited information about the relationship between the inferior alveolar canal and the mandibular third molars, cortication of the inferior alveolar canal and the detailed anatomy of the third molar. Several clinical studies have shown the specific radiographic signs detected in panoramic radiographs which shows close relationship between the inferior alveolar canal and mandibular third molars. 4 Radiographic signs include- root darkening, roots deflection, root narrowing, dark and bifid root, interruption of the white line, diversion and narrowing of the of inferior alveolar canal.5-However, opinion regarding the frequencies of the above mentioned signs for predicting the inferior alveolar nerve position or clinical complications such as paraesthesia after removal of mandibular third molar. If the panaromic radiographs indicates there is a close relationship between the third molar and the mandibular canal, supplement investigation using CT may be recommended to verify $\underline{1,6,7} \mathrm{CT}$ are higher radiation dose and financial cost in compare to panaromic view. 8

CBCT (cone beam computed tomography) has reduced the radiation dose, offers high spatial resolution and decreases costs. CBCT seems to be more accurate imaging modality for determining the relationship of the third molar to the inferior alveolar canal. This examination should help the surgeon to evaluate the difficulty of the surgery and to choose the most appropriate surgical technique, for example where to remove bone, how to split the tooth 
and in what direction the roots can be lifted. In most cases, a conventional radiographic examination with plain radiography will suffice. In the complicated cases, the conventional has its short comings and relevant anatomical relationship cannot be accurately displayed.

\section{Materials and Methods}

This study was done from June 2015 to July 2016. Sixty patients who consulted with impacted mandibular third molars whose panoramic radiographs show a close approximate between inferior alveolar canal and the mandibular third molars were included in the study. Only patients those have a close relationship between the inferior alveolar nerve and one or both impacted mandibular third molars, diagnosed from digital panoramic radiographs, underwent additional CBCT imaging and were enrolled in this study. The assessment of the outcome variables was done prior to surgical intervention. A detailed clinical history for each sample was taken.

\section{Results}

Out of 60 patients in spatial relation to CBCT, 36 patients had canal to buccal root of mandibular third molar. Twenty patients had canal on lingual root of mandibular third molar. The canal in 2 patients was determined inferiorly placed in relation to mandibular $3^{\text {rd }}$ molar. In the rest 2 patients, the canal was in interradicular position.

Table I shows the relationship between panoramic radiographic sings and the anatomic location of the canal found on CBCT. Out of 60 patients, 20 patients showed superimposition of tooth roots on inferior alveolar canal among in buccal to mandibular root and lingual to mandibular third molar root. Among 19 patients with interruption of the radiopaque borders of the canal had buccal to mandibular third molar root and lingual to mandibular third molar. Out of 10 patients had darkening of the roots, majority in buccal to mandibular third molar root. Among 11 patients with narrowing of the canal most of them in buccal to mandibular third molar root.

Out of 28 patients with masioangular, 5 subjects had presence of contact on CBCT, which is statistically significant (among 10 patients with vertical pattern of impaction 1 patients had contact on CBCT, which is statistical significant. Out of 14 patients horizontal impaction patients, 9 patients had contact on CBCT which is not statistical significant and among 5 patients distoangular impaction 2 had contact on CBCT, which is not statistical significant (Table II).

\section{Discussion}

The results show that horizontally impacted mandibular third molars have intimate relation with inferior alveolar canal. This study reveals superimposition of the third molar roots on the inferior alveolar canal had the highest frequency of 20 subjects. Interruption of the radiopaque border of the canal was found in 19 subjects, narrowing of the inferior alveolar canal was found in 11 subjects and darkening of the roots was found in 10 subjects.

In a study found that mesioangular (35.9\%) type of impaction was most common and distoangular (5\%) less common. 9 In another study it was found that vertical type of impaction was most common and horizontal (9.4\%) was least common type.? Panoramic signs of superimposition of the roots on the canal along with interruption of radiopaque border of canal were most frequent while panoramic signs of superimposition in conjunction with narrowing and deviation of the inferior alveolar canal were least frequent respectively found in another study.10 On the other hand, had shown that darkening of roots $(42.9 \%)$ was the most common finding followed by narrowing of inferior alveolar canal (28.9\%).11 In different studies reported that the root of lower third molar was in contact with the inferior alveolar canal 85 and 94\% respectively.1,3 It was found in another study that

\section{Table I}

Relationship between panoramic radiographic sings and the anatomic location of the canal found on CBCT

\begin{tabular}{|c|c|c|c|c|c|}
\hline \multirow[t]{2}{*}{ Findings of orthopantomogram } & \multirow[t]{2}{*}{$\mathrm{n}$} & \multicolumn{4}{|c|}{ Position of inferior alveolar canal on CBCT } \\
\hline & & $\begin{array}{l}\text { Buccal to mandibular } \\
\text { third molar root }\end{array}$ & $\begin{array}{l}\text { Lingual to mandibular } \\
\text { third molar root }\end{array}$ & $\begin{array}{l}\text { Interradicular of } \\
\text { the root }\end{array}$ & $\begin{array}{l}\text { Inferior to the } \\
\text { root }\end{array}$ \\
\hline $\begin{array}{l}\text { Superimposition of tooth roots on } \\
\text { inferior alveolar canal }\end{array}$ & 20 & 9 & 8 & 2 & 1 \\
\hline $\begin{array}{l}\text { Interruption of the radioopaque bor- } \\
\text { ders of the canal }\end{array}$ & 19 & 10 & 8 & 0 & 1 \\
\hline Darkening of the roots & 10 & 8 & 2 & 0 & 0 \\
\hline Narrowing of the canal & 11 & 9 & 2 & 0 & 0 \\
\hline
\end{tabular}




\section{Table II}

Association of impaction of type (OPG evaluation) and proximity of the roots to the IAC (CBCT findings)

\begin{tabular}{|l|ccc|}
\hline $\begin{array}{l}\text { Pattern of impaction } \\
\text { on orthopantomogram }\end{array}$ & $\mathrm{n}$ & $\begin{array}{c}\text { Contact on CBCT } \\
(\mathrm{n}=27)\end{array}$ & $\begin{array}{c}\text { Separate on CBCT } \\
(\mathrm{n}=33)\end{array}$ \\
\hline Masioangular & 28 & 5 & 23 \\
Vertical & 10 & 1 & 9 \\
Horizontal & 14 & 9 & 5 \\
Distoangular & 5 & 2 & 3 \\
Others & 3 & 1 & 2 \\
\hline
\end{tabular}

contact with the canal was 36\%.10 Different studies have suggested that anatomical proximity of third molar roots to the neurovascular bundle increases the risk of inferior alveolar nerve injury. $\underline{.12,13}$ In another study, it was found that loss of radiopaque border and deviation of canal was an indicator of contact with the canal and increased risk of inferior alveolar nerve injury. $\underline{5}$

The findings of CBCT was encouraging in detecting anatomical position of inferior alveolar canal and impacted mandibular third molar tooth and is definitely superior to orthopantomogram. Therefore, CBCT is a promising test in preoperative assessment of impacted mandibular third molar position and inferior alveolar canal. It helps the surgeon to plan the surgery.

\section{Conclusion}

CBCT is needed in addition to preoperative orthopantomogram for a patient who may undergo third molar extraction.

\section{References}

1. Ohman A, Kmjarvi K, Blombock U, Flygare L. Preoperative radiographic evaluation of lower third molars with computed tomography. Dentomaxillofac Radiol. 2006; 35: 30-35.

2. Gulicher D, Gerlach KL. Sensory impairment of the lingual and inferior alveolar nerves following removal of impacted mandibular third molars. Int J Oral Maxillofac Surg. 2001; 30: 306-12.

3. Ghaeminia H, Meijer GJ, Soehardi A, Borstlap WA, Mulder J, Berge SJ. Position of the impacted third molar in relation to the mandibular canal: Diagnostic accuracy of cone beam computed tomography compared with panoramic radiography. Int J Oral Maxillofac Surg. 2009; 38: 964-71.

4. Ghaeminia H, Meijer GJ, Soehardi A, Borstlap WA, Mulder J, Vlijmen OJC. The use of cone beam CT for the removal of wisdom teeth changes the surgical approach compared with panoramic radiography: A pilot study. Int J Oral Maxillofac Surg. 2011; 40: 834-39.

5. Umar G, Bryant C, Obisesan O, Rood JP. Correlation of the radiological predictive factors of inferior alveolar nerve injury with cone beam computed tomography findings. Oral Surg. 2010; 3: 72-82.

6. Maegawa H, Sano K, Kitagawa Y, Ogasawara T, Miyauchi K, Sekine J, Inokuchi T. Preoperative assessment of the relationship between the mandibular third molar and the mandibular canal by axial computed tomography with coronal and sagittal reconstructions. Oral Surg Oral Med Oral Pathol Oral Radiol, Endod. 2003; 96: 639-46.

7. Monaco G, Montevecchi M, Bonetti GA, Antonella MR, Checchi L. Reliability of panoramic radiography in evaluating the topographic relationship between the mandibular canal and impacted third molars. J Am Dent Assoc. 2004; 135: 312-20.

8. Schulze D, Heiland M, Thurmann H, Adam G. Radiation exposure during mid facial imaging using 4- and 16-slice computed tomography, cone beam computed tomography systems and conventional radiography. Dentomaxillofac Radiol. 2004; 33: 83-86.

9. Hasegawa T, Ri S, Shigeta T, Akashi M, Imai Y, Kakei Y. Risk factors associated with inferior alveolar nerve injury after extraction of the mandibular third molar: A comparative study of preoperative images by panoramic radiography and computed tomography. Int J Oral Maxillofac Surg. 2013; 42: 843-51.

10. Tantanapornkul W, Okouchi K, Fujiwara Y, Yamashiro Y, Maruoka Y, Ohayashi N. A comparative study of cone beam computed tomography and conventional panoramic radiography in assessing the topographic relationship between the mandibular canal and impacted third molars. Oral Surg Oral Med Oral Pathol Oral Radiol Endod. 2007; 103: 253-59.

11. Katakam SK, Shankar U, Thakur D, Reddy TPK. Hari KR, Janga D. Comparison of orthopantomography and computed tomography image for assessing the relationship between impacted mandibular third molar and mandibular canal. J Contemp Dent Pract. 2012; 13: 819-23.

12. Nakayama K, Nonoyama M, Takaki $Y$, Kagawa T, Yuasa K, Izumi K. Assessment of the relationship between impacted mandibular third molars and inferior alveolar nerve with dental 3-dimensional computed tomography. J Oral Maxillofac Surg. 2009; 67: 2587-91.

13. Nakamori K, Fujiwara K, Miyazaki A, Tomihara K, Tsuji M, Nakai M. Clinical assessment of the relationship between the third molar and the inferior alveolar canal using panoramic images and computed tomography. J Oral Maxillofac Surg. 2008; 66: 2308-13. 